\title{
Performance investigation of parabolic trough solar collector integrated with thermal energy storage system
}

\author{
Nitin A. Kumbhar*, S.R. Shinde and V.S. Shinde \\ Department of Mechanical Engineering, Trinity College of Engineering \& Research, Savitribai Phule Pune University, Maharashtra, India.
}

Accepted 15 June 2016, Available online 20 June 2016, Special Issue-5 (June 2016)

\begin{abstract}
In the family of the solar collectors, parabolic trough collector presently getting significant interest for a wide range of applications from air heating applications, hot water production to steam generation and industrial process heat applications. The high level of concentration achievable with parabolic trough collector diminishes the drawback coupled with the constraint of some level of tracking as compared to flat plate collectors. Also, parabolic trough collectors are simpler than other collectors. At the same time, time dependent nature of the solar energy can be eliminated by introducing thermal energy storage system in the parabolic trough collector. This work has been carried out to investigate the performance of parabolic trough collector based air heating system integrated with latent thermal energy storage system. The instantaneous parabolic trough collector efficiency has been evaluated without and with incorporation of thermal energy storage system with variation in mass flow rate of air from 0.0022 $\mathrm{kg} / \mathrm{sec}$ to $0.0044 \mathrm{~kg} / \mathrm{sec}$. The result revels that introducing latent thermal energy storage system in the parabolic trough collector enhances the collector efficiency by $17 \%$ at the same time it gives the required performance even at low solar radiation intensity. The collector efficiency increases with increase in mass flow rate of air.
\end{abstract}

Keywords: Parabolic Trough Collector (PTC), PCM, Latent Thermal Energy Storage System

\section{Introduction}

The demand of the energy is increasing at drastic rate due to overall growth of the world. At the same time pressure on the conventional energy sources such as fossil fuels are increasing. The efforts are being made to reduce burden on the conventional energy sources by introducing the renewable energy sources in the energy consumption systems. Now a day's solar energy has been utilized for the domestic, industrial and power generation purposes. For low and medium temperatures applications the use of solar energy has been increased. Flat plate collector and evacuated tube collector based air and water heating systems are introduced in the domestic and industrial applications. Flat plate collector and evacuated tube collector based systems have certain disadvantages from the point of view of the higher temperature applications. Concentrating based collector systems have higher thermal efficiencies compared with non-concentrating collector. The disadvantage related to the solar energy is unavailability in night time which restricts its application for its full time use.

Among the different types of solar collectors, parabolic trough collector (PTC) is currently getting significant attention for a broad range of applications

*Corresponding author: Nitin A. Kumbhar from household hot water production to steam generation for power and engineering process heat generation. The suggestion of most of the researchers is that the parabolic trough collector concept should receive the maximum priority for commercial development for low temperature solar process heat applications. The high degree of attentiveness attainable with parabolic trough collector diminishes the drawback connected with the requirement of some level of tracking as compared to flat plate collectors Also, parabolic trough collectors are simpler than other collectors.

The major factor that restricts the use of solar energy for various applications is that, it is timedependent energy source. Thus, solar systems require energy storage to provide energy during the night and cloudy periods. Thus for higher temperature applications or lager mass flow rate fluids the parabolic trough collector can be implemented. At the same time by incorporating the thermal energy storage system in the given applications it is possible to make use of the solar energy in the night time or cloudy conditions. Latent thermal energy storage systems are more applicable in the area of thermal energy storage systems due to its high energy storage capacity. The PCM based energy storage system can be integrated with parabolic trough collector. 
Considering the above, the present work aims to investigate the performance of the parabolic trough collector based air heating system with integration of thermal energy storage system.

\section{Literature Review}

Muhammad Aamir khan et al developed high performance solar collector for drying of agricultural products.

Stiling et al. investigated concentrating solar panels in his research paper titled "Performance evaluation of an enhanced fruit solar dryer using concentrating panels". Concentrating solar panels (CSP) improve the process of solar drying Roma tomatoes. This paper presents a performance comparison between two mixed-mode solar dryers. The dryers were identically constructed, however one of the dryers utilized mobile and easily adjustable flat concentrating solar panels to maximize incident solar energy on the dryer. Temperatures inside the dryer that utilized the concentrating solar panels were approx. $10{ }^{\circ} \mathrm{C}$ higher than those in the normal dryer during the majority of a sunny day testing period. This increase in temperature led to shorter Roma tomato drying times in the dryer with CSP.

Blake Ringeisen et al made an attempt to overcome the challenges of the high humidity, intermittent clouds, and haze often present in tropical climates, this paper investigates the effectiveness of adding a concave solar concentrator built from low-cost, locally available materials to a typical Tanzanian solar crop dryer.

Jiang Tao Liu et al[ developed novel parabolic trough concentrating solar heating for cut tobacco drying system was established. The opening width effect of $\mathrm{V}$ type metal cavity absorber was investigated. The result shows that this parabolic trough concentrating solar heating will be one of the heat recourse candidates for cut tobacco drying system.

The efficient alternative energy utilization must invariably involve energy storage to be able to cater to fluctuation demand and at the same time to obtain a higher performance from energy sources. Energy storage system also assumed greater significance in the context of waste heat utilization or in the situation dealing with intermittent supplies of input energy like solar energy. Phase change material (PCM) is one of the most preferred from to store thermal energy. The results from previous studies indicated that PCMs can be adjusted to have a melting within the ranges which are most suitable for fruits and leaves drying applications.

Sharma et al. presented a research paper titled "Review on thermal energy storage with phase change materials and applications." The use of a latent heat storage system using phase change materials (PCMs) is an effective way of storing thermal energy and has the advantages of high-energy storage density and the isothermal nature of the storage process. PCMs have been widely used in latent heat thermal storage systems for heat pumps, solar engineering, and spacecraft thermal control applications. There are large numbers of PCMs that melt and solidify at a wide range of temperatures, making them attractive in a number of applications. This paper also summarizes the investigation and analysis of the available thermal energy storage systems incorporating PCMs for use in different applications.

Morrison, Abdel Khalik and Jurinak in their different studies evaluated the performance of airbased solar heating systems utilizing phase change energy storage unit. The main objectives of their work were: (i) to determine the effect of the PCM latent heat and melting temperature on the thermal performance of air-based solar heating systems and (ii) to develop empirical model of significant phase change energy storage (PCES) units. The main conclusion was that the PCM should be selected on the basis of melting point rather than its latent heat and also found that air-based system utilizing sodium sulfate decahydrate as a storage medium requires roughly one-fourth the storage volume of a pebble bed and one half the storage volume of a water tank.

Ghoneim and Klein compared theoretically the performance of phase change and sensible heat storage for air and water based solar heating systems. Sodium sulphatedecahydrate and paraffins were used as phase change materials and noted the similar results as by Jurnik and AdbelKhalik.

Buddhi et al.have discussed both advantages and disadvantages of various experimental techniques used to determine the behavior of these materials in melting and solidification, including their thermo physical properties such as melting point, heat fusion, thermal conductivity and density. Recently, several works have been carried out in order to study the thermal characteristics of paraffin during solidification and melting process, their studies found that paraffin based PCMs have very low thermal conductivity leading to slow charging and discharging, hence heat transfer enhancement techniques are required in order to bring paraffin based PCMs to the successful applications.

Enibe [10] had undertaken design, development and performance evaluation of a natural convection solar air heater with phase change material energy storage. The daytime performance of the system under no-load conditions was tested under natural environmental conditions involving ambient temperature variations in the range $19-41{ }^{\circ} \mathrm{C}$ and daily global irradiation in the range 4.9-19.9 $\mathrm{MJ} \mathrm{m}^{2}$. Peak temperature rise of the heated air was about $15 \mathrm{~K}$ while peak cumulative useful efficiency was about $50 \%$. The system is suitable for use as a solar cabinet crop dryer for aromatic herbs, medicinal plants and other crops, which do not require direct exposure to sunlight.

\section{Experimental Investigation}

This section elaborates the experimental set up, geometrical data of the parabolic trough collector, 
thermal energy storage system, and test methodology and performance parameters related to the work which has been carried out.

\subsection{Experimental Set up:}

An experimental model has been constructed to test the performance characteristics of parabolic trough collector integrated with latent thermal energy storage systems. Efficiency of parabolic trough collector is calculated with variation in mass flow rate of air with and without integration of latent thermal energy storage system.

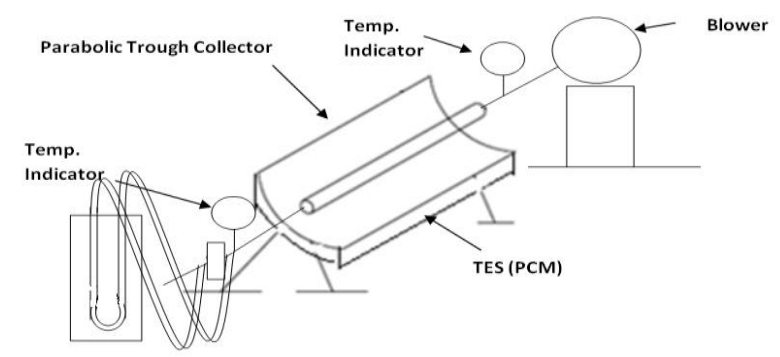

Fig.1 Schematic layout of proposed PTC with TES

In the present work an experimental investigation has been carried out to study the performance of a solar PTC integrated with a latent thermal energy storage system. The thermal energy storage system is integrated with PTC at the bottom of the reflector. The air is supplied to the PTC by centrifugal blower through flow control valve. The temperature sensors are mounted at the inlet and outlet of the collector. The efficiency of the parabolic trough collector is calculated with variable mass flow rate of air with and without incorporation of the thermal energy storage system. The mass flow rate of air is measured with the help of orifice meter. The schematic layout the experimental system is shown in Fig.1

In order to measure the mass flow rate of air passing thorough the absorber tube the provision has been made at the rare end by installing the orifice meter. The mass flow rate of air is varied with the help of flow control valve.

The parabolic trough collector with manual tracking is used for air heating purpose.

Specifications of the parabolic trough collector are:

- Reflecting material: Aluminum

- Effective aperture area: $0.28 \mathrm{~m}^{2}$

- Aperture width:0.4 m

- Absorber tube material:Copper

- Glass tube outerdiameter (OD): $0.025 \mathrm{~m}$

- Glass tube innerdiameter (ID): $0.030 \mathrm{~m}$

- Length of copper tube $\left(\mathrm{L}_{\mathbf{c}}\right): 1.4 \mathrm{~m}$

- Glazing material: Glass tube

- Outer diameter (OD) :0.060m

- Thickness (t) :0.002m

- Length of glass tube $\left(\mathrm{L}_{\mathrm{g}}\right): 1.4 \mathrm{~m}$
In Experimental setup, parabolic trough collector having an aperture area $0.28 \mathrm{~m}^{2}$ and focal length $0.1 \mathrm{~m}$ is used for solar air heating. Cylindrical parabolic collector is used to heat the air by manual tracking.

From the standard available reflective stainless steel sheets, a pilot trough-receiver unit is developed. Aluminium steel sheet $0.7 \mathrm{~m} \times 0.4 \mathrm{~m}$ is chosen as reflecting surface. The collector is designed with simple parabolic equations. From geometrical relations of the parabolic section, the cross section for the parabolic trough is traced as shown in Fig. 2. The sheet is curved to form a parabolic trough module of $0.7 \mathrm{~m}$ length and $0.4 \mathrm{~m}$ aperture width with effective aperture area of $0.28 \mathrm{~m}^{2}$. The simple parabolic equation in Cartesian coordinates is,

$x^{2}=4 f y$

Table. 2Geometrical data of the parabolic trough model

\begin{tabular}{|c|c|c|c|}
\hline Sr. No. & Item & Symbol & Value \\
\hline 1 & Length & $L$ & $0.7 \mathrm{~m}$ \\
\hline 2 & Aperture & $a$ & $0.4 \mathrm{~m}$ \\
\hline 3 & Rim angle & $\psi$ & $90^{0}$ \\
\hline 4 & Focal length & $f$ & $0.1 \mathrm{~m}$ \\
\hline 5 & Receiver diameter & $d$ & $0.025 \mathrm{~m}$ \\
\hline 6 & Concentration ratio & $C r$ & 6 \\
\hline 7 & Concentrator height & $h$ & $0.25 \mathrm{~m}$ \\
\hline
\end{tabular}

From equation (1), the height of the parabola in terms of the focal length and aperture diameter is

$(a / 2)^{2}=4 f h$ or

$h=a^{2} / 16 f$

The rim angle $\left(\psi_{\text {rim }}\right)$ is given by

$\tan \left(\psi_{\text {rim }}\right) / 2=(a / 4 f)$

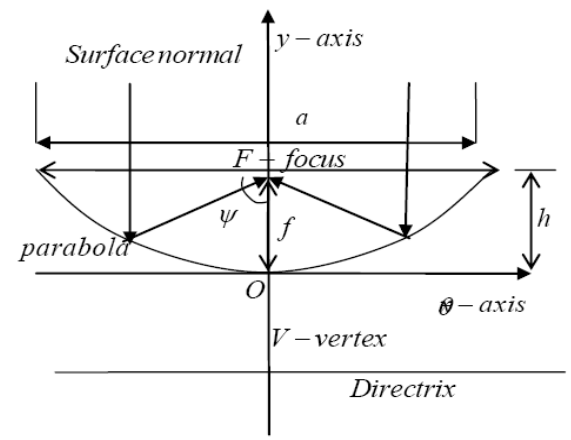

Fig.No.2:-Cross section of parabolic trough

Geometrical concentration ratio $\mathrm{C}_{\mathrm{g}}$ is defined as "the area of the collector aperture Aa, divided by the surface area of the receiver Ar.

$\mathrm{C}=\mathrm{A}_{\mathrm{a}} / \mathrm{A}_{\mathrm{r}}$

Calculations for geometrical concentration ratio:

We know the aperture area of parabolic trough collector $=\mathrm{Ap}=\mathrm{L} * \mathrm{~W}=0.7 * 0.4$ 
Concentrating Ratio (C) $=$ (Effective Aperture Area)/(Absorber tube surface Area)

$\mathrm{C}=\left(\left(\mathrm{W}-\mathrm{D}_{0}\right) \mathrm{L}\right) /\left(\pi^{*} \mathrm{D}_{0} * \mathrm{~L}\right)$

From the selected values of the concentration ratio and the ratio between the concentrator length to its aperture width, the values of the aperture area, the receiver surface area, the aperture width, the receiver outside diameter, and the length of the concentrator were calculated from equation 1 to 4 . For this model the focal point is selected at the aperture line i.e. the collector height $(\mathrm{h})$ is equal to the focal length (f) with rim angle $90^{\circ}$. The selected data of the designed model has the following values as given by table 1 .

Calculations for geometrical concentration ratio are as follows, Aperture area of parabolic trough collector $=$ $A_{p}=L^{*} W=0.7 * 0.4=0.28 \mathrm{~m}^{2}$

Concentrating Ratio $(\mathrm{C})=$ (Effective Aperture Area) / (Absorber tube surface Area)

$\mathrm{C}=((\mathrm{W}-\mathrm{Do}) \mathrm{L}) /\left(\pi^{*}\right.$ Do $\left.* \mathrm{~L}\right)$

$\mathrm{C}=6$

\subsection{Test Methodology}

Test methodology with which this work has been carried out is described below

Testing has been carried out for given mass flow rate of air with and without integration of thermal energy storage system throughout the day. Initially testing has been carried out without integration of thermal energy storage system for mass flow rates of air as mentioned throughout the day. The mass flow rate of air passing through the absorber tube is varied from 0.0022 to $0.0044 \mathrm{~kg} / \mathrm{sec}$. For given mass flow rate of air, inlet and outlet temperature of air has been recorded with time interval of half an hour throughout the day from $10.00 \mathrm{am}$ to $6.00 \mathrm{pm}$. The intensity of solar radiation has been measured with the solar pyrometer during testing period within interval of half an hour. The readings of the solar radiation intensity, mass flow rate of air, inlet and outlet temperatures of air are recorded at a time. It has been proposed to carry out the testing for developed experimental system, without and with integration of the thermal energy storage system. With integration of the thermal energy storage system in parabolic trough collector, the same testing methodology has been implemented same as that of without integration of TES. The only difference between these two methodologies are in case of the integration of TES with PTC, the air is passed through the thermal energy storage system at the time at which the intensity of the solar radiation is not sufficient to maintain out let temperature of air. The instantaneous parabolic trough collector efficiency has been calculated at the respective time intervals throughout the day for parabolic trough collector with and without integration of thermal energy storage system.

\section{Performance Parameters}

The performance of the developed experimental system has been evaluated in terms of the variation in the instantaneous parabolic trough collector efficiency with respect to time, with and without integration of the thermal energy storage system for various mass flow rates of the air. The tests have been carried out on different days such that variation in the intensity of solar radiation with respect to time on different days is close to each other. Performance of the experimental system has been evaluated with and without activation of the thermal energy storage system in terms of parabolic trough collector efficiency with and without integration of TES system.

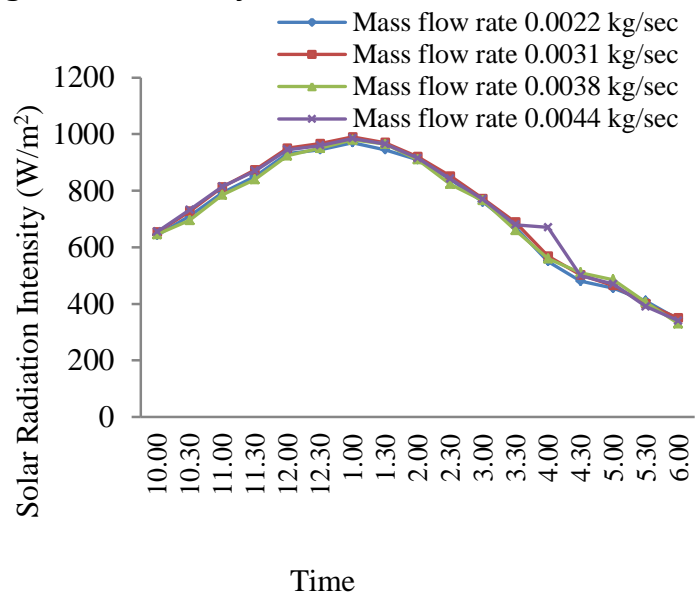

Fig.3 Variation of intensity of solar radiation with time during testing of PTC without TES

Fig.3 shows the variation in the intensity of solar radiation with respect to time for different mass flow rates of the air on respective testing day during testing of parabolic trough collector without thermal energy storage system. The variation of the solar radiation intensity with time on different days shows the close agreement with each other. Which indicated the same amount of energy is supplied to the developed experimental system for various testing conditions so that the performance can be compared with each for same input conditions.

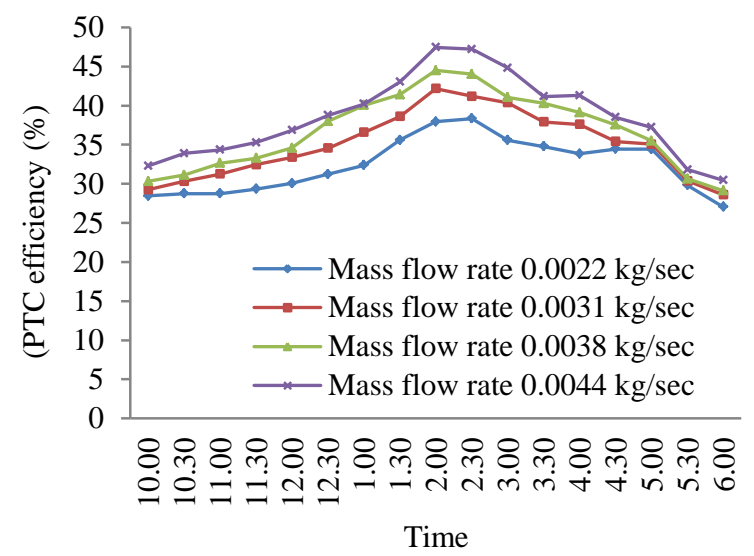

Fig.4 Variation of PTC efficiency with time during testing of PTC without TES 
It has been observed that the instantaneous collector efficiency of parabolic trough collector initially increases with time and then decreases. With increase in mass flow rate of air instantaneous collector efficiency of parabolic trough collector increases. The maximum collector efficiency is observed corresponding to the maximum intensity of solar radiation.

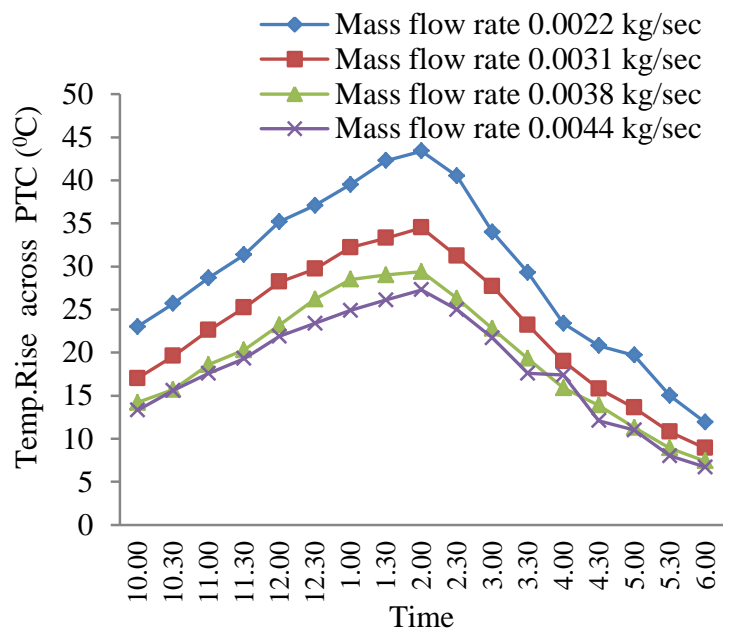

Fig.5 Variation of temperature rise across PTC with time during testing of PTC without TES.

Fig.5 depicts the variation of the temperature rise across the parabolic trough collector with time without thermal energy storage system. The graphs are plotted for the different mass flow rate varies from 0.0022 $\mathrm{kg} / \mathrm{sec}$ to $0.0044 \mathrm{~kg} / \mathrm{sec}$. With increase in mass flow rate of air the temperature rise across the PTC increases with time and then decreases. Corresponding to maximum intensity of solar radiation the maximum temperature rise is obtained at maximum mass flow rate of air in case of parabolic trough collector without thermal energy storage system. Additionally it has been observed that the temperature rise across the PTC without TES continuously decreases after $4.00 \mathrm{pm}$ due to decrease in the intensity of solar radiation.

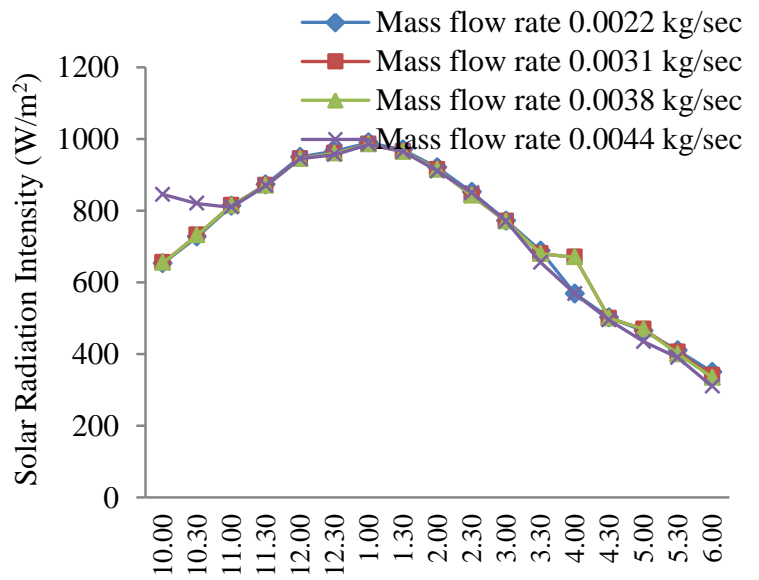

Time

Fig.6 Variation of intensity of solar radiation with time during testing of PTC with TES
Fig.6 shows the variation in the intensity of solar radiation with respect to time for different mass flow rates of the air on respective testing day during testing of parabolic trough collector with thermal energy storage system. The variation of the solar radiation intensity with time on different days shows the close agreement with each other. Which indicated the same amount of energy is supplied to the developed experimental system for various testing conditions so that the performance can be compared with each for same input conditions. There is close agreement between the variations in intensity of solar radiation with time for PTC without and with integration of thermal energy storage system.

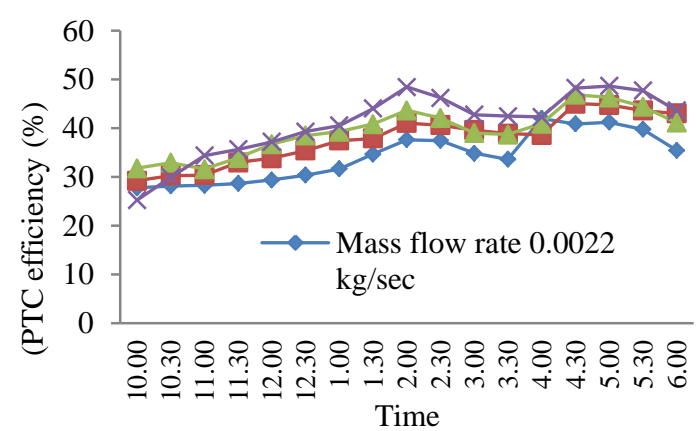

Fig.7 Variation of PTC efficiency with time during testing of PTC with TES

Fig.7 shows that the instantaneous collector efficiency of parabolic trough collector initially increases with time and then decreases. With increase in mass flow rate of air instantaneous collector efficiency of parabolic trough collector increases.

The maximum collector efficiency is observed corresponding to the maximum intensity of solar radiation in case of the PTC with thermal energy storage system. After comparing the results of the variation in PTC efficiency with time for PTC with and without TES system revels that, for same mass flow rate of air the PTC efficiency with TES shows more temperature rise across and PTC efficiency after 4.00 pm when the TES system has been activated.

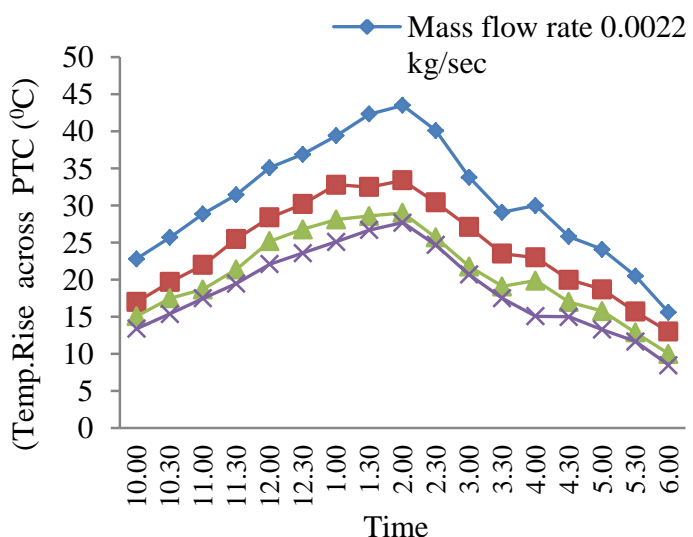

Fig.8 Variation of temperature rise across PTC with time during testing of PTC with TES and without TES 
Fig.8 shows the variation of the temperature rise across the parabolic trough collector with time with thermal energy storage system. The graphs are plotted for the different mass flow rate varies from 0.0022 $\mathrm{kg} / \mathrm{sec}$ to $0.0044 \mathrm{~kg} / \mathrm{sec}$. With increase in mass flow rate of air the temperature rise across the PTC increases with time and then decreases.

Corresponding to maximum intensity of solar radiation the maximum temperature rise is obtained at maximum mass flow rate of air in case of parabolic trough collector without thermal energy storage system. Additionally it has been observed that the temperature rise across the PTC with TES is more than the temperature rise without TES after $4.00 \mathrm{pm}$ even due to decrease in the intensity of solar radiation is that the energy stored in the thermal energy stored system has been retrieved from the TES which leads to increase in the temperature rise and PTC efficiency compared with PTC without thermal energy storage system.

The solar energy stored in the TES system during day time is retrieved from TES after $4.00 \mathrm{pm}$ by passing the air through the thermal energy storage system instead of the PTC. This leads to increase in the air outlet temperature and enhanced PTC efficiency even at low solar radiation intensity.

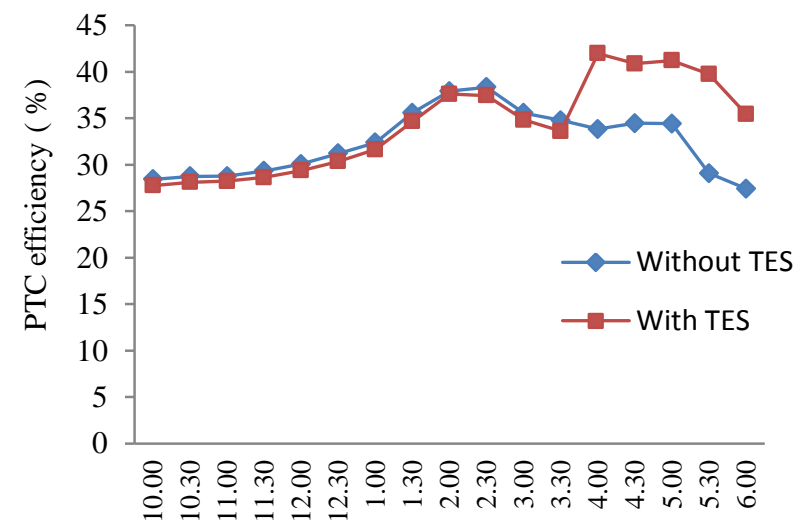

Time

Fig. 9 Variation of PTC efficiency with time during testing of PTC with TES and Without TES at mass flow rate $0.0022 \mathrm{~kg} / \mathrm{sec}$

Fig. 9 shows the comparison between the variations in the parabolic trough collector efficiency with time for PTC with and without TES system at mass flow rate of $0.0022 \mathrm{~kg} / \mathrm{sec}$. The graph shows that after $4.00 \mathrm{pm}$ as energy stored in TES system has been retrieved which leads to increase in the efficiency of PTC with TES system. Fig. 10 and 11 shows the comparison between the variation in the instantaneous PTC efficiency with time with and without incorporation of the thermal energy storage system. Same trend of increase in PTC efficiency after $4.00 \mathrm{pm}$ has been observed for mass flow rate of air as 0.0031 and $0.0044 \mathrm{~kg} / \mathrm{sec}$ with incorporation of thermal energy storage system.

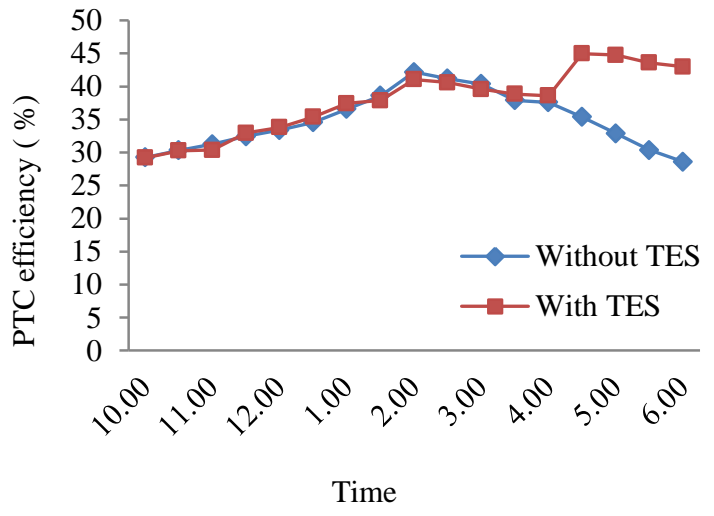

Fig.10 Variation of PTC efficiency with time during testing of PTC with TES and Without TES at mass flow rate $0.0031 \mathrm{~kg} / \mathrm{sec}$

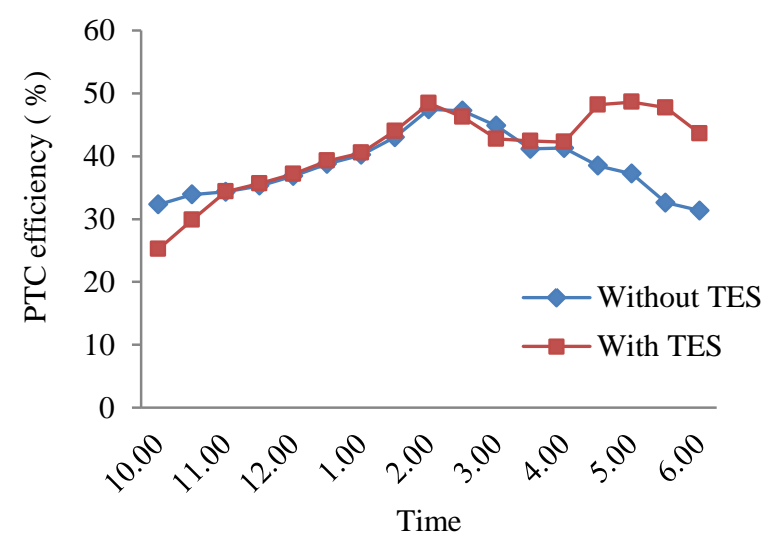

Fig.11 Variation of PTC efficiency with time during testing of PTC with TES and Without TES at mass flow rate $0.0044 \mathrm{~kg} / \mathrm{sec}$

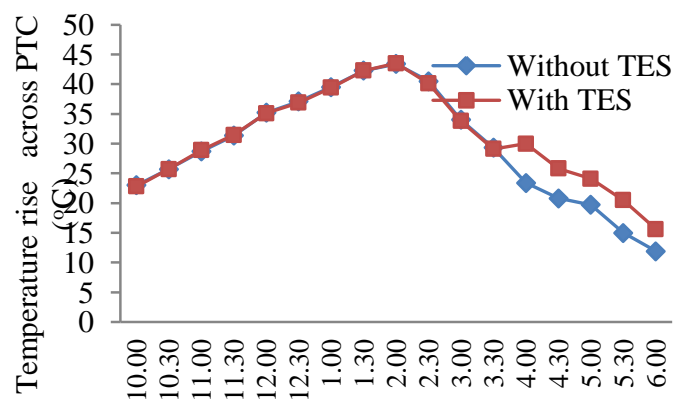

Time

Fig.12 Variation of temperature rise across PTC with time during testing of PTC with TES and Without TES at mass flow rate $0.0022 \mathrm{~kg} / \mathrm{sec}$

Fig. 12 shows the comparison between the variations in the temperature rise across the collector with time for PTC with and without TES system at mass flow rate of $0.0022 \mathrm{~kg} / \mathrm{sec}$. The graph shows that after $4.00 \mathrm{pm}$ as energy stored in TES system has been retrieved which leads to increase in the temperature rise across PTC with TES system. The reason behind the temperature rise across the PTC with thermal energy storage system is that the energy stored in the TES system has been retrieved and supplied to air which passes through the thermal energy storage system. Fig. 
13 to 15 shows same behavior of enhanced PTC efficiency with TES system after $4.00 \mathrm{pm}$ for mass flow rate of air $0.0022 \mathrm{~kg} / \mathrm{sec}, 0.0031 \mathrm{~kg} / \mathrm{sec}, 0.0038 \mathrm{~kg} / \mathrm{sec}$ and $0.0044 \mathrm{~kg} / \mathrm{sec}$.

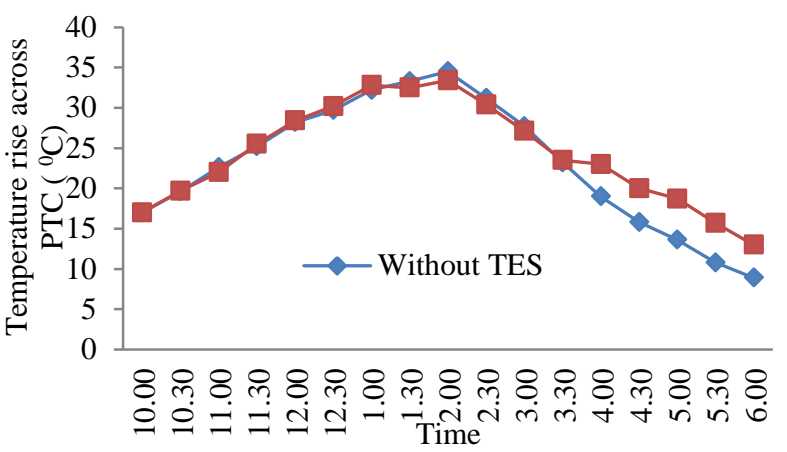

Fig.13 Variation of temperature rise across PTC with time during testing of PTC with TES and Without TES at mass flow rate $0.0031 \mathrm{~kg} / \mathrm{sec}$

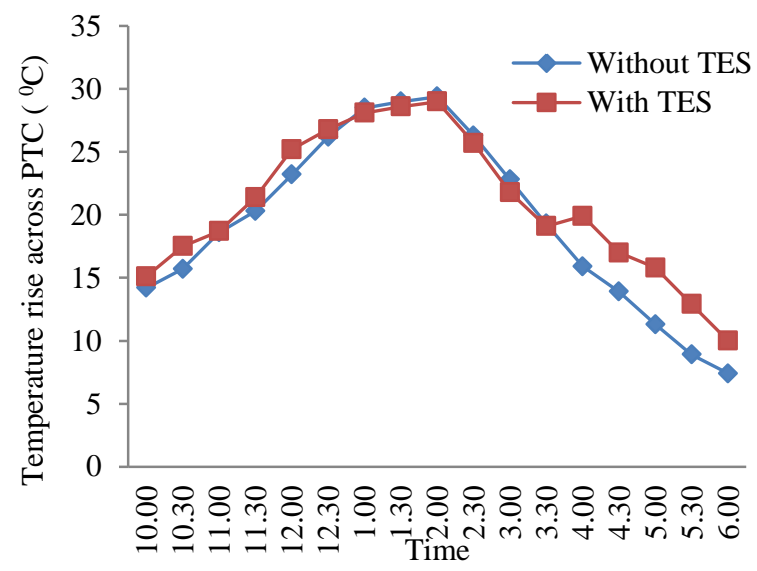

Fig.14 Variation of temperature rise across PTC with time during testing of PTC with TES and Without TES at mass flow rate $0.0038 \mathrm{~kg} / \mathrm{sec}$

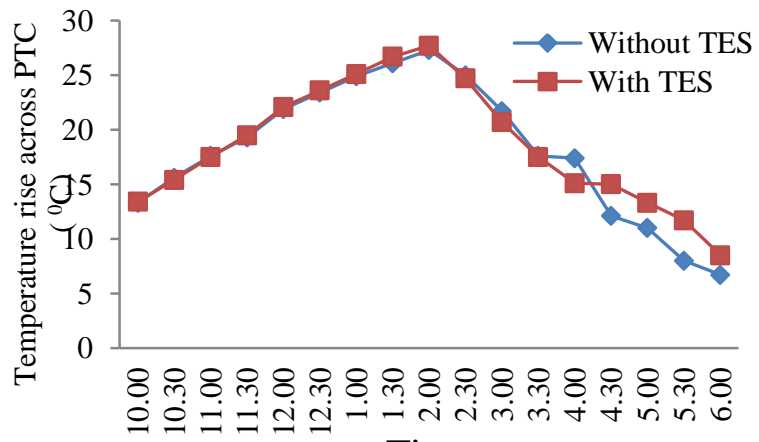

Time

Fig.15 Variation of temperature rise across PTC with time during testing of PTC with TES and Without TES at mass flow rate $0.0044 \mathrm{~kg} / \mathrm{sec}$

Thus it has been observed that with incorporation of the thermal energy storage system in parabolic trough collector, higher the temperature rise across the collector and higher collector efficiency is obtained compared with PTC without thermal energy storage system.

\section{Conclusions}

Following conclusions can be drawn from the work carried out in context of the integration of the thermal energy storage system with parabolic trough collector.

1) Integration of the thermal energy storage system with parabolic trough collector leads to increase in outlet temperature of air and the instantaneous collector efficiency at low solar radiation intensity after sunset. The maximum enhancement in the parabolic trough collector efficiency has been observed at mass flow rate of $0.0044 \mathrm{~kg} / \mathrm{sec}$ is $17 \%$.

2) Energy can be stored in the thermal energy storage system during the daytime can be retrieved from the same in order to increase the outlet temperature of the air even at low solar radiation intensity which occurs after sunset.

3) Higher temperature rise across the PTC is observed at maximum mass flow rate of $0.0044 \mathrm{~kg} / \mathrm{sec}$ when parabolic trough collector is integrated with the thermal energy storage system. The maximum temperature rise obtained at this mass flow rate of air is $10^{\circ} \mathrm{C}$.

4) Thus for air heating systems the parabolic trough collector based systems finds more suitable than flat plate collector based system in context of the temperature rise. Extending the same collector with integration of thermal energy storage system further leads to supply the air at higher temperature and enhanced collector efficiency.

5) The proposed work can be applied to solar drying applications where use of solar energy can be extended in night time when solar radiations are not available.

\section{References}

Muhammad Aamir khan,2013), Development of a Small Scale Concentrating Parabolic trough Solar Collector for Drying Purposes Journal of Engineering International, Volume 1, No .

James stiling and Pieter stroeve. (2012) Performance evaluation of an enhanced fruit solar dryer using concentrating panels. Energy for sustainable development. Vol.16, pp. 224-230.

Daniel M. Blake, Luc Moensa, Mary Jane Halea, Henry Pricea, David Kearney, and Ulf Herrmannc,(2002), "New Heat Transfer and Storage Fluids for Parabolic Trough Solar Thermal Electric Plants", September 4-6.

Jiang Tao Liu, Ming Li, Qiong Fen Yu, and De Li Ling, (2014),A Novel Parabolic Trough Concentrating Solar Heating for Cut Tobacco Drying System, International Journal of Photoenergy, Article ID 209028, 10 pages.

AtulSharma,V.V. Tyagi ,C.R. Chen, D. Buddhi,(2009),Review on therma energy storage with phase change materials and applications, Renewable and Sustainable Energy Reviews, 13, 318-345.

Morrison DJ, Abdel Khalik SI.,(1978), Effects of phase change energy storage on the performance of air-based and liquid-based solar heating systems. Solar Energy;20:57-67.

Ghoneim AA, Klein SA.,(1989), The effect of phase change material properties on the performance of solar air-based heating systems. Solar Energy; 42(6):441-7.

Jurinak JJ, AdbelKhalik SI.,(1979), On the performance of air-based solar heating systems utilizing phase change energy storage. Solar Energy; 24:503-22.

Buddhi D, Sharma SD, Sharma A.,(2003),Thermal performance evaluation of a latent heat storage unit for late evening cooking in a solar cooker having three reflectors. Energy Convers Manage; 44(6):809-17.

Enibe SO.,(2002), Performance of a natural circulation solar air heating system with phase change material energy storage. Renew Energy: 27:69-86.

Zhou G, ZhangY, Zhang Q, Lin K, Di H.,(2007), Performance of a hybrid heating system with thermal storage using shape-stabilized phasechange material plates. ApplEnergy ;84(10):1068-77.

Alkilani, M. M., Sopian, K., Sohif, M., Alghoul, M.A.,(2009),Output Air Temperature Prediction in a Solar Air Heater Integrated with Phase Change Material, European Journal of Scientific Research, 27 (2009), 3, pp. 334-341. 